\title{
The Multidimensional Work Motivation Scale: Validation evidence in seven languages and nine countries
}

Marylène Gagné, Jacques Forest, Maarten Vansteenkiste, Laurence CrevierBraud, Anja van den Broeck, Ann Kristin Aspeli, Jenny Bellerose, Charles Benabou, Emanuela Chemolli, Stefan Tomas Güntert, Hallgeir Halvari, Devani Laksmi Indiyastuti, Peter A. Johnson, Marianne Hauan Molstad, Mathias Naudin, Assane Ndao, Anja Hagen Olafsen, Patrice Roussel, Zheni Wang \& Cathrine Westbye

To cite this article: Marylène Gagné, Jacques Forest, Maarten Vansteenkiste, Laurence Crevier-Braud, Anja van den Broeck, Ann Kristin Aspeli, Jenny Bellerose, Charles Benabou, Emanuela Chemolli, Stefan Tomas Güntert, Hallgeir Halvari, Devani Laksmi Indiyastuti, Peter A. Johnson, Marianne Hauan Molstad, Mathias Naudin, Assane Ndao, Anja Hagen Olafsen, Patrice Roussel, Zheni Wang \& Cathrine Westbye (2015) The Multidimensional Work Motivation Scale: Validation evidence in seven languages and nine countries, European Journal of Work and Organizational Psychology, 24:2, 178-196, DOI: 10.1080/1359432X.2013.877892

To link to this article: http://dx.doi.org/10.1080/1359432X.2013.877892

Published online: 05 Feb 2014.

Џll Article views: 1515

View Crossmark data ¿
Submit your article to this journal $₫$ 


\title{
The Multidimensional Work Motivation Scale: Validation evidence in seven languages and nine countries
}

\author{
Marylène Gagné ${ }^{1}$, Jacques Forest ${ }^{2}$, Maarten Vansteenkiste ${ }^{3}$, Laurence Crevier-Braud ${ }^{4}$, Anja \\ Van den Broeck ${ }^{5}$, Ann Kristin Aspeli ${ }^{6}$, Jenny Bellerose ${ }^{7}$, Charles Benabou ${ }^{2}$, Emanuela \\ Chemolli $^{1}$, Stefan Tomas Güntert ${ }^{8}$, Hallgeir Halvari ${ }^{6}$, Devani Laksmi Indiyastuti ${ }^{9}$, Peter A. \\ Johnson $^{10}$, Marianne Hauan Molstad ${ }^{6}$, Mathias Naudin ${ }^{11}$, Assane Ndao ${ }^{12}$, Anja Hagen \\ Olafsen $^{6}$, Patrice Roussel ${ }^{13}$, Zheni Wang ${ }^{1}$, and Cathrine Westbye ${ }^{6}$
}

${ }^{1}$ School of Psychology, University of Western Australia, Perth, Australia

${ }^{2}$ Department of Organization and Human Resource Management, UQAM School of Management Sciences, Université du Québec à Montréal, Montréal, Canada

${ }^{3}$ Department of Developmental, Personality and Social Psychology, University of Gent, Gent, Belgium

${ }^{4}$ Department of Psychology, Université du Québec à Montréal, Montréal, Canada

${ }^{5}$ Department of Economy and Management, Hogeschool Universiteit Brussel, Brussels, and KU Leuven, Leuven,

Belgium

${ }^{6}$ Faculty of Economics and Social Science, Høgskolen i Buskerud og Vestfold, Kongsberg, Norway

${ }^{7}$ Department of Psychology, Université de Montréal, Montréal, Canada

${ }^{8}$ Psychology of Work in Organization and Society Research Group, Swiss Federal Institute of Technology, Zurich,

Switzerland

${ }^{9}$ Faculty of Economics and Business, Universitas Gadjah Mada, Yogyakarta, Indonesia

${ }^{10}$ Institute of Work Psychology, University of Sheffield, Sheffield, United Kingdom

${ }^{11}$ International Institute of Commerce and Development, Université Panthéon Assas - Paris II, Paris, France

${ }^{12}$ Faculty of Economics and Management Sciences, Université Cheikh Anta DIOP, Dakkar, Sénégal

${ }^{13}$ Department of Management and Human Resources, Université Toulouse 1, Toulouse, France

\begin{abstract}
Self-determination theory proposes a multidimensional conceptualization of motivation comprising autonomous and controlled forms. Whereas autonomous motivation relates positively to individuals' optimal functioning (e.g., well-being, performance), controlled motivation is less beneficial. To be able to use self-determination theory in the field of organizational behaviour, the Multidimensional Work Motivation Scale was developed and tested using data from 3435 workers in seven languages and nine countries. Factorial analyses indicated that the 19-item scale has the same factor structure across the seven languages. Convergent and discriminant validity tests across the countries also indicate that the psychological needs for autonomy, competence, and relatedness as well as the theoretically derived antecedents to work motivation (e.g., leadership and job design) are predictably related to the different forms of motivation, which in turn are predictably related to important work outcomes (e.g., well-being, commitment, performance, and turnover intentions). Implications for the development of organizational research based on self-determination theory are discussed.
\end{abstract}

Keywords: Cross-cultural; Work motivation; Self-determination theory; Validation; Intrinsic motivation; Extrinsic motivation; Autonomous motivation; Controlled motivation.

Correspondence should be addressed to Marylène Gagné, School of Psychology, University of Western Australia, 35 Stirling Highway, Crawley 6009, WA, Australia. E-mail: marylene.gagne@uwa.edu.au

The first five authors are listed in order of contribution, the other authors are listed in alphabetical order.

Preparation of this article was facilitated through several grants to the different authors: Fonds Québécois de la Recherche sur la Société et la Culture to the first and second authors, a grant from the Social Sciences and Humanities Research Council of Canada to the first and second authors, and a grant from the Association Nationale Recherche Technologie (France) to Mathias Naudin. 
In a time of globalization, contemporary theories of organizational behaviour need to be applicable across cultural, economic, and labour conditions. Research consequently needs to focus on the cross-cultural validation of motivation theories (Steers, Mowday, \& Shapiro, 2004). One theory that is receiving increasing crosscultural support in various life domains is self-determination theory (SDT; Deci \& Ryan, 1985a). SDT offers a multidimensional conceptualization of motivation, allowing for the assessment of both the level and quality of motivation. The present research focused on validating a new measure that captures motivation using SDT in the work context, in an attempt to overcome recurrent validity and psychometric problems of previous measures. We validated the newly proposed scale across different cultures to test its psychometric properties in several languages. Specifically, the nine countries (i.e., Canada, Belgium, France, Senegal, United Kingdom, Norway, Switzerland, China, and Indonesia) in which data were collected varied in terms of cultural background, economic situation, political regime, and labour conditions, but the samples also varied in terms of industry, organizational structure, and jobs. Though we did not assess prevailing cultural values, Hofstede's (2001) studies point out that the participating samples vary in terms of collectivism and power distance, though some of these values are changing in the younger generations (e.g., Wang \& Gagné, 2013). We begin with providing a description of SDT and describing the new scale before testing its validity.

\section{SELF-DETERMINATION THEORY}

SDT proposes a multidimensional view on motivation and specifies how these different types of motivation can be promoted or discouraged. Three major categories of motivation are discerned. First, amotivation is defined as the absence of motivation towards an activity. Second, intrinsic motivation is defined as doing an activity for its own sake, that is, because it is interesting and enjoyable in itself. Third, extrinsic motivation refers to engaging in the activity for instrumental reasons, such as receiving rewards and approval, avoiding punishments or criticism, boosting one's self-esteem, or reaching a personally valued goal. Given this diversity of instrumental reasons, SDT specifies different subtypes of extrinsic motivation, which vary in their internalization. Internalization refers to taking in a value-driven or goal-driven activity that was initially regulated by external factors, such as rewards or punishments, so that it becomes internally regulated (Deci \& Ryan, 2000). A first form of extrinsic motivation, which is completely noninternalized, is external regulation. It refers to doing an activity to obtain rewards or avoid punishments administered by others. Then, introjected regulation refers to the regulation of behaviour out of internally pressuring forces, such as ego-involvement, shame, and guilt. This form of internalization is experienced as controlling (Ryan \& Connell, 1989). Finally, identified regulation refers to doing an activity because one identifies with its value or meaning and accepts it as one's own, such that this form of internalization is volitional. Identification differs from intrinsic motivation in that the activity is not done out of inherent satisfaction, but for the instrumental value it represents.

Several researchers have merged external and introjected regulations into a controlled motivation composite score, and combined identified and intrinsic motivation into an autonomous motivation composite score (e.g., Vansteenkiste, Lens, De Witte, De Witte, \& Deci, 2004). In contrast to controlled motivation and amotivation, autonomous motivation has been found to yield the most desirable behavioural, attitudinal, and affective outcomes (Deci \& Ryan, 2008). However, depending on the research question, it is sometimes better to use the firstorder factors (i.e., external, introjected, identified and intrinsic motivation), as these motivational subtypes have in some cases been found to yield different behavioural and attitudinal outcomes in certain domains, like environmentalism (Pelletier, Tuson, Green-Demers, Noels, \& Beaton, 1998) and politics (Koestner, Losier, Vallerand, \& Carducci, 1996). Therefore, a scale tapping into each of the different motivation forms is necessary.

\section{THE MULTIDIMENSIONAL WORK MOTIVATION SCALE}

Well validated SDT-based motivation scales already exist in other life domains, such as academics and sports (e.g., Grolnick \& Ryan, 1987; Guay, Vallerand, \& Blanchard, 2000; Pelletier et al., 1995; Ryan \& Connell, 1989; Vallerand et al., 1992). As for the work domain, Blais, Brière, Lachance, Riddle, and Vallerand (1993) published the first SDT-based work motivation measure in French. Internal reliability problems with the external regulation subscale (Cronbach's alphas in the $.50 \mathrm{~s})$, and face validity problems encouraged Tremblay, Blanchard, Villeneuve, Taylor, and Pelletier (2009) as well as Gagné et al. (2010) to improve the scale (simultaneously in French and English). These scales, however, still had some problems, as we discuss later, which led to the development and validation of the Multidimensional Work Motivation Scale (MWMS), presented herein. The MWMS assesses work motivation at the domain level of analysis (Vallerand, 1997), which differs from other scales that measure work motivation for different tasks within a particular job (e.g., Fernet, Senécal, Guay, Marsh, \& Dowson, 2008). The MWMS intends to improve over previous scales in four ways.

First, most SDT-based measures of motivation follow the SDT tradition of asking people why they do an activity (e.g., practising a sport, pursuing an education) by asking them to rate statements reflecting different types of behavioural regulations (Ryan \& Connell, 
1989). For example, following the stem "Why do you do this job?", previous scales included items such as "for the pay check" (Blais et al., 1993) or "for the income it provides me" (Tremblay et al., 2009). Although such a stem might work in other domains such as sports, in the work domain, it may be problematic. As employment is defined as a contract of service between an employee rendering a service to an employer in exchange for money, people are likely to report that they do work for money. In line with SDT and the core elements of effort (i.e., intensity, duration, and direction; De Cooman, De Gieter, Pepermans, Jegers, \& Van Acker, 2009), items of the MWMS more strongly and clearly reflect the contingency between workers' effort expenditures and the rewards they receive. Accordingly, we modified the stem of the MWMS for "Why do you or would you put efforts into your current job?" to reflect the amount of effort people put into their job. This new stem also focuses on actual ("do") and intended ("would") efforts, in order to more fully capture people's motives (both actual and latent) to do their job.

A second improvement over previous scales is that the external and introjected regulation subscales of the MWMS were created to balance out approach and avoidance motives, thereby avoiding the possible confound between external/introjected regulations and approach/avoidance motivation (Assor, Vansteenkiste, \& Kaplan, 2009). In previous scales external regulation items were mostly approach oriented, focusing on the pursuit of rewards and praise, whereas introjected items were mostly avoidance oriented, focusing on the avoidance of guilt and shame. The MWMS includes both approach and avoidance for external and introjected regulation. In addition, we included external regulation items focusing on material (e.g., money) as well as social rewards (e.g., praise), because both are important in the work context (Stajkovic \& Luthans, 1997).

Third, we made sure that no items tapped into other related constructs, such as the satisfaction of the needs for autonomy, competence, and relatedness, intrinsic and extrinsic values, and harmonious and obsessive passion (Grouzet et al., 2005; Vallerand et al., 2003; Van den Broeck, Vansteenkiste, De Witte, Soenens, \& Lens, 2010; Vansteenkiste et al., 2007). For example, previous amotivation items resembled low satisfaction of the need for competence (e.g., "I ask myself this question, I don't seem to be able to manage the important tasks related to this work"; Tremblay et al., 2009), and identification items resembled the intrinsic value of affiliation (e.g., "Because, in my opinion, it is one of the best ways to meet people; Pelletier et al., 1995). Finally, in order to achieve cross-cultural equivalence, items were written so that they could be endorsed in most cultures. For example, previous work motivation scales (Blais et al., 1993; Tremblay et al., 2009) have included an item to measure introjected regulation that stated "Because I have to be a 'winner' in life", which was poorly endorsed in collectivistic and high power-distance cultures.

\section{Testing for convergent and discriminant validity}

To test for convergent and discriminant validity, we followed Gagné and Deci's (2005) model, in which managerial behaviours and job design affect the satisfaction of three basic psychological needs, which in turn influence autonomous motivation more than controlled motivation. Autonomous motivation in turn is theorized to increase employee functioning. Unlike in Gagné and Deci, however, we tried to make predictions for each type of regulation based on the theory. We chose outcomes that have been studied in SDT research and in the field of organizational psychology, namely, affective commitment (Gagné, Chemolli, Forest, \& Koestner, 2008), well-being (i.e., vitality; Ryan \& Frederick, 1997), psychological distress (emotional exhaustion; Fernet, Gagné, \& Austin, 2010), job effort (Kuvaas, 2006), and turnover intentions (Gagné, 2003). As there is solid evidence from research in other life domains that SDT is cross-culturally valid (e.g., Chirkov \& Ryan, 2001; Chirkov, Ryan, Kim, \& Kaplan, 2003; Deci et al., 2001; Sheldon et al., 2004), we expected to find that relations between antecedents and outcomes of work motivation would be equivalent across the sampled countries.

Measures of need satisfaction were included in five language subsamples. Across the different language samples, it was expected that autonomy, competence, and relatedness need satisfaction would be positively related to intrinsic and identified regulation, and that autonomy and relatedness need satisfaction would be unrelated to introjected and external regulation, as they are incompatible with feeling pressured. Following the logic of locus of control theory (Rotter, 1954), competence need satisfaction was expected to relate positively to all motivation forms except amotivation, to which all three needs were expected to relate negatively.

With respect to leadership, autonomy-supportive managerial behaviour was expected to relate positively to both forms of autonomous motivation, not to relate to any form of controlled motivation, and to relate negatively to amotivation (Baard, Deci, \& Ryan, 2004; Deci et al., 2001). We also used the theory of full range leadership (Bass \& Avolio, 1989), using Avolio, Bass, and Jung's (1999) four emerging leadership styles: transformational leadership, contingent reward leadership, active management by exception and passive leadership (which merges passive management by exception and laissez-faire leadership). ${ }^{1}$ It was expected that transformational leadership (which shares many components

${ }^{1} \mathrm{~A}$ CFA of our own data revealed good support for the same factor structure. 
with autonomy support; Wang \& Gagné, 2013) would be positively related to both forms of autonomous motivation, unrelated to any form of controlled motivation, and negatively related to amotivation. Contingent reward leadership should be positively related to both controlled and autonomous forms of motivation, and negatively related to amotivation, because items measuring contingent reward leadership focus exclusively on providing clear directions and positive feedback in exchange for performance (Bass \& Riggio, 2006). Research on the provision of structure has shown that it can promote autonomous motivation in school children (Farkas \& Grolnick, 2010), and research on positive feedback has found that it relates positively to intrinsic motivation, in contrast to tangible contingent rewards (which are not assessed in this subscale), which tend to be negatively related to intrinsic motivation (Deci, Koestner, \& Ryan, 1999). Active management by exception, defined as active monitoring and punishment behaviour, was expected to be negatively related to autonomous motivation and amotivation, and positively related to both forms of controlled motivation. Passive leadership, defined as noncontingent punishment behaviour and neglect, would be negatively related to autonomous and controlled motivation, and positively related to amotivation. Finally, with respect to job design, it was expected in line with most job design theories (Parker \& Ohly, 2008 ) that an enriched job would be positively related to autonomous motivation, because it adds stimulation and meaning, be unrelated to controlled motivation as it should not increase or decrease pressure but instead add stimulation, and be negatively related to amotivation.

Consistent with SDT and also with past research, it was expected that autonomous motivation would be positively correlated to positive outcomes (i.e., affective commitment, well-being, and job effort), and negatively to negative outcomes (i.e., turnover intentions and psychological distress). We expected that controlled forms of motivation would be negatively related to well-being, unrelated to affective commitment, and positively related to job effort, based on the idea that these forms of motivation are fuelled by pressure. Finally, we expected amotivation to have the opposite pattern from autonomous motivation with the outcomes. Notably, with regards to performance, we tested whether identified motivation may be more strongly related to various aspects of work performance than intrinsic motivation as some job tasks are not very interesting or enjoyable and therefore unlikely to generate intrinsic motivation (Gagné \& Deci, 2005).

For reasons of feasibility and economy, we split these hypotheses across the samples. Though this method does not allow for a full cross-cultural comparison of the strength of relations between constructs, it provides a preliminary test of the convergent and discriminant validity of the new scale. As there is solid evidence from research in other life domains that SDT is crossculturally valid (e.g., Chirkov et al., 2003; Deci et al., 2001), we expected to find that relations between antecedents and outcomes of work motivation would be equivalent across the sampled countries.

\section{METHOD}

\section{Phase 1: Creation of the Multidimensional Work Motivation Scale}

In brief, an initial pool of 55 items were tested. This pool included items from Gagné et al. (2010), as well as new items created simultaneously in French, English, and Dutch by the first five authors. These items were tested among a heterogeneous set of 500 employees in Canada (in French and English) and in Belgium (in Dutch). We conducted exploratory factor analyses and examined relations between each item and feelings of autonomy, competence, and relatedness (Van den Broeck et al., 2010). Items were retained that (1) adequately loaded on their respective factor across the three languages (i.e., loadings $>.50$ ), (2) did not cross-load on other subscales (i.e., loadings $<.20$ ), and (3) were logically most strongly related to the three needs. Based on these analyses, 32 items were kept, none of which were from Gagné et al. (2010).

\section{Phase 2: Factorial structure of the MWMS}

We conducted a second round of data collection in nine countries (see Table 1 for sample characteristics) to examine the factor structure of the MWMS. Participants completed a questionnaire containing the MWMS along with other scales, either in a paper-andpencil format or through a Web-based platform, during or outside of working hours. Anonymity or confidentiality was ensured and consent was obtained from all participants. The goal was to obtain a succinct measure with internally consistent subscales for amotivation, external regulation (with the approach and avoidance items of social and material external regulation items all loading onto one factor), introjected regulation (with approach/avoidance items on one factor), identified regulation, and intrinsic motivation, that is a five-factor structure. Additionally, we aimed to achieve a threefactor second-order structure based on SDT's principle that external and introjected regulations represent controlled motivation, identified regulation and intrinsic motivation represent autonomous motivation, and amotivation stands on its own (Deci \& Ryan, 2000).

Exploratory factor analyses on the French, English, and Dutch samples led to the scale being reduced to a final 19 items with three to six items per factor (see Appendix). Confirmatory factor analyses were then conducted to (1) validate the fit in the French, English, and Dutch samples, (2) examine the fit of the factor structure 


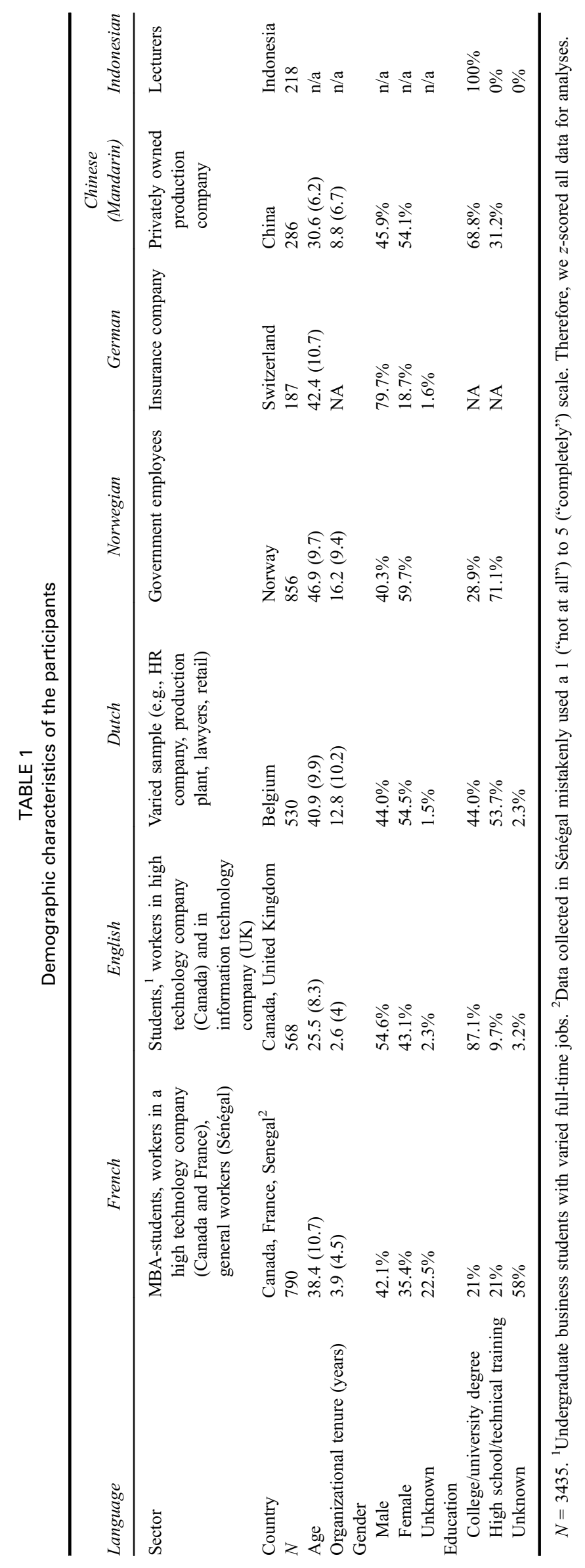


TABLE 2

Fit statistics of the hypothesized and the alternative models

\begin{tabular}{|c|c|c|c|c|c|c|c|c|}
\hline & Language & $N$ & $S-B \chi^{2}$ & df & $C F I$ & RMSEA & RMSEA $90 \% C I$ & Model AIC \\
\hline \multirow[t]{3}{*}{ Hypothesized model } & French & 790 & 562.68 & 143 & .91 & .061 & $.056, .066$ & 276.68 \\
\hline & English & 568 & 633.01 & 143 & .87 & .078 & $.072, .084$ & 347.01 \\
\hline & Dutch & 530 & 578.12 & 143 & .85 & .076 & $.069, .082$ & 292.12 \\
\hline \multirow{3}{*}{ Alternative model 1} & French & 790 & 463.94 & 141 & .93 & .054 & $.048, .059$ & 181.94 \\
\hline & English & 568 & 509.96 & 141 & .90 & .068 & $.062, .074$ & 227.96 \\
\hline & Dutch & 530 & 231.78 & 141 & .97 & .035 & $.027, .043$ & 50.22 \\
\hline \multirow[t]{3}{*}{ Alternative model 2} & French & 790 & 544.89 & 141 & .91 & .060 & $.055, .066$ & 262.88 \\
\hline & English & 568 & 609.03 & 141 & .88 & .077 & $.070, .083$ & 327.03 \\
\hline & Dutch & 530 & 564.92 & 141 & .86 & .074 & $.067, .080$ & 264.92 \\
\hline \multirow[t]{3}{*}{ Alternative model 3} & French & 790 & 289.23 & 143 & .97 & .036 & $.030, .042$ & 3.23 \\
\hline & English & 568 & 473.33 & 143 & .91 & .064 & $.057, .070$ & 187.33 \\
\hline & Dutch & 530 & 516.43 & 143 & .87 & .070 & $.064, .077$ & 230.43 \\
\hline Configural invariance & French, English and Dutch combined & 1888 & 1400.01 & 417 & .91 & .061 & $.058, .065$ & 566.01 \\
\hline Metric invariance & French, English and Dutch combined & 1888 & 1550.14 & 443 & .90 & .063 & $.060, .066$ & 664.14 \\
\hline Structural invariance & French, English and Dutch combined & 1888 & 1732.58 & 463 & .90 & .066 & $.063, .069$ & 806.58 \\
\hline
\end{tabular}

$\mathrm{S}-\mathrm{B}=$ Satorra-Bentler; $d f=$ degrees of freedom; $\mathrm{CFI}=$ comparative fit index; RMSEA = root mean square error of approximation; $\mathrm{CI}=$ confidence interval; Model $\mathrm{AIC}=$ Akaike's information criterion.

in other languages, and (3) examine correlations between the subscales (Ryan \& Connell, 1989). Items were translated from English to Norwegian, German, Indonesian, and Chinese, using a backtranslation method. Subscales that are theoretically contiguous in terms of level of internalization should correlate positively, whereas scales that are nonadjacent should not correlate. Amotivation and intrinsic motivation should be negatively correlated (e.g., Vallerand et al., 1992).

Results. A few univariate and multivariate outliers (less than $5 \%$ ) were found and deleted from the datasets. Missing values (below 5\% at the item level) were replaced using a regression imputation procedure. CFAs were conducted using robust maximum likelihood estimation because the normalized Mardia coefficients for multivariate kurtosis ranged from 44.52 to 126.41 across the different samples. First, the five-factor model was tested in French, English, and Dutch. No cross-loadings were hypothesized and the covariance between the latent factors of intrinsic motivation and external regulation was fixed at 0 since SDT postulates that their correlation should be close to zero or nonsignificant (Gagné et al., 2010; Ryan \& Connell, 1989). ${ }^{2}$ Fit for this model was within acceptable range in the three languages (see Table 2). Three alternative models were also tested within these languages. The first alternative model consists of seven factors where a second-order factor was created for material and social external regulation subfactors. The second alternative model replicates the fivefactor model but adds second-order factors for autonomous and controlled motivation. The third alternative model is a combination of the first two alternative

\footnotetext{
${ }^{2}$ Freeing up this correlation leads to lower fit indices and the estimate of the parameter is nonsignificant.
}

models. Support was found for the third alternative model in the French and English samples, though it was weaker in Dutch. The second model fitted the data less well. In contrast, the fit of the first alternative model was within acceptable range in the three languages (see Table 2 and Figure 1). Because its Akaike's information criterion (AIC) statistic was lower (Kline, 2005), this model was preferred over the other models and chosen as the configural model to use for invariance analyses (Byrne, 2006). Standardized pattern coefficients ranged from .48 to .96 across the three languages. Correlations between the latent variables ranged from -.45 to .82 , from -.53 to .80 , and from -.38 to .75 in the French, English, and Dutch samples, respectively.

We then ran CFAs on the four other languages. Results showed that the chosen model was acceptable in Norwegian and Indonesian, and close to acceptable in German and Chinese (see Table 3). Lagrange-Multiplier tests revealed that the fit of the model in these samples could be improved by releasing a correlation between the error terms of the third and fourth items of the introjection subscale, German, $\chi^{2}(140)=231.84, \mathrm{CFI}=.92$, RMSEA $=.059$, Chinese, $\chi^{2}(140)=304.30$, CFI $=.94$, RMSEA $=.078$. In all, the MWMS is well represented through five latent factors representing intrinsic motivation, identified regulation, introjected regulation (including approach and avoidance orientation items in one first-order factor), external regulation as a second-order factor (where social approach and social avoidance are combined, and where material approach and material avoidance are combined in another first-order factor), and amotivation.

Reliabilities and correlation patterns. As shown in Table 4, out of 35 alpha coefficients only two (identified and introjected regulation in German) were below .70, 


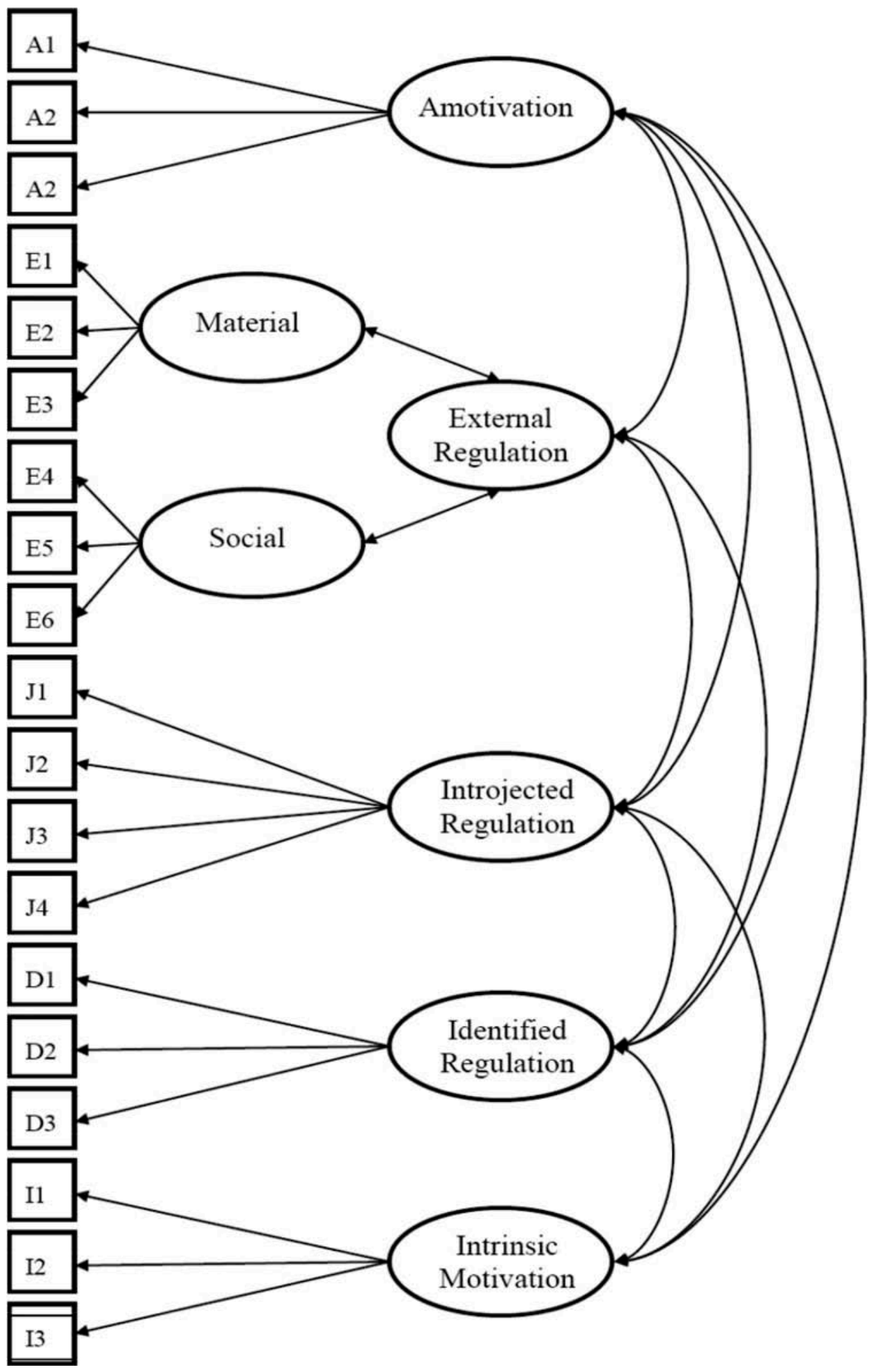

Figure 1. Factor structure of the MWMS (alternative model 1).

and a majority were above .80 . Correlations between the factors generally followed the hypothesized correlational patterns whereby adjacent scales are positively related, whereas nonadjacent subscales are less strongly related (Ryan \& Connell, 1989). In all samples, amotivation and intrinsic motivation were negatively related, as expected.
Phase 3: Invariance tests in seven languages

Invariance analyses were conducted to compare the structure of the scale across languages (Cheung \& Rensvold, 2002) using the alternative model 1 as a baseline model. We tested whether the factor structure 
TABLE 3

Fit statistics for each language separately and for invariance tests

\begin{tabular}{lccccccccc}
\hline Model & $N$ & $S-B \chi^{2}$ & df & CFI & RMSEA & RMSEA, 90\% CI & CFI configural invariance & CFI metric invariance & CFI structural invariance \\
\hline Norwegian & 856 & 664.68 & 141 & .94 & .066 & $.061, .071$ & .92 & .92 & .91 \\
German & 187 & 268.99 & 141 & .89 & .070 & $.057, .082$ & .89 & .90 & .90 \\
Chinese & 286 & 493.51 & 141 & .88 & .094 & $.085, .102$ & .91 & .90 & .88 \\
Indonesian & 218 & 328.62 & 141 & .93 & .078 & $.067, .089$ & .89 \\
\hline
\end{tabular}

RMSEA for all invariance analyses were between .032 and .039 .

(configural invariance), the pattern coefficients (metric invariance), and whether the correlations between latent factors (structural invariance) were invariant across the different languages under examination (Vandenberg \& Lance, 2000). We did not test whether the latent factor means were invariant across languages because it would be normal for means to vary depending on the nature of the job tasks, leadership styles, job design, and other work-related factors.

Results. Invariance was first tested with the French, English, and Dutch samples. Results showed that the MWMS had an invariant configuration in the three languages, invariant factor loadings (i.e., metric invariance), and invariant correlations between the latent factors (i.e., structure invariance; see Table 2). We then tested the configural model for each combination of four languages (the three base languages and adding one more, one at a time). In all cases, except German, this model obtained a good fit (see Table 3). The German version yielded a slightly lower fit for configural invariance, indicating that the correlated error term may be necessary to adequately model the data in this language. We therefore stopped at this point with the German sample. In order to verify metric invariance, we compared the measurement models in the different combinations of four languages (see Table 3). We considered a language to be invariant when the CFI was above .90 and when the change in CFI between the configural and measurement model did not decrease by more than .01 (Cheung \& Rensvold, 2002). The Norwegian, Chinese, and Indonesian versions were metrically invariant. The same method was used to test for structural invariance. Only the Norwegian version was found to be structurally invariant. We can therefore say that the MWMS items are understood in an equivalent manner in at least six of the languages in which it was developed.

\section{Phase 4: Convergent and discriminant validity}

Table 5 presents the antecedents and outcomes that were measured in each sample. Notably, some of the measures were included in only one of the subsamples in a particular language, which made it impossible to test the Gagné and Deci (2005) model using mediation analyses.
For example, one French subsample included autonomy support, whereas another included need satisfaction. We therefore used zero-order correlations.

Need satisfaction. The Work-Related Basic Need Satisfaction scale (W-BNS; Van den Broeck et al., 2010) was used in the Canadian (French and English), Dutch, and Norwegian samples. It measures the satisfaction of the needs for autonomy (six items, e.g., "I feel like I can be myself at my job"), competence (six items, e.g., "I feel competent at my job"), and relatedness (six items, e.g., "At work, I feel part of a group"). The Basic Need Satisfaction at Work Scale (BNS-W; Deci et al., 2001) was used in the Chinese sample, and also measures the needs for autonomy (seven items, e.g., "I feel like I can pretty much be myself at work"), competence (six items, e.g., "I don't feel very competent at work" (reversed coded), and relatedness (eight items, e.g., "People at work care about me"). Items were answered on a 1 ("totally disagree") to 5 ("totally agree") Likert scale in both measures. Cronbach's $\alpha$ were $.76, .80, .85$, .82 , and .83 for the French, English, Dutch, Norwegian, and Chinese samples, respectively.

Autonomy support. The autonomy support subscale from the Perceived Autonomy Support Scale for employees (Moreau \& Mageau, 2012; nine items, e.g., "My supervisor gives me many opportunities to make decisions in my work") was used in the Canadian (French) sample, and the Work Climate Questionnaire was used in the German and Norwegian samples (Baard et al., 2004; six items, e.g., "I feel that my manager provides me choices and options"). Items from the two scales were answered on a 1 ("strongly disagree") to 7 ("strongly agree") Likert scale. Cronbach's $\alpha$ were .86, .92 , and .94 for the French, German, and Norwegian samples, respectively.

Supervisor's leadership style. The Multifactor Leadership Questionnaire ${ }^{3}$ (Bass \& Avolio, 1989) was used in the Canadian (French and English) samples, and

\footnotetext{
${ }^{3}$ Used with permission, Mind Garden, Inc., 1690 Woodside Road \#202, Redwood City, CA 94061 USA http://www.mindgarden.com/ from the Multifactor Leadership Questionnaire by Bernard M. Bass and Bruce J. Avolio. Copyright 1995 by Bernard M. Bass and Bruce J. Avoli.
} 


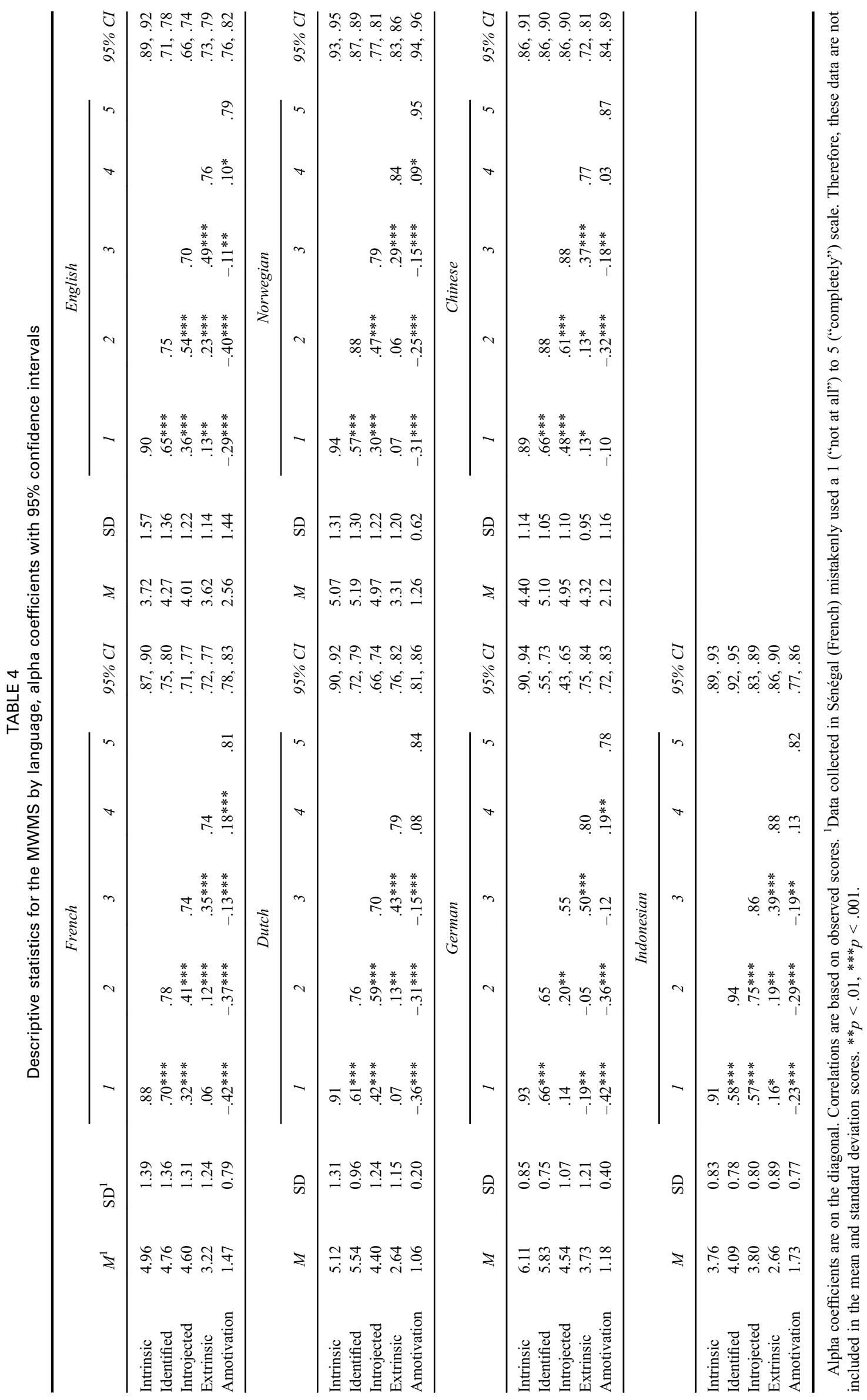


TABLE 5

Constructs measured and analyses conducted in each sample

\begin{tabular}{|c|c|c|c|c|c|c|c|}
\hline & French & English & Dutch & Norwegian & German & Indonesian & Chinese \\
\hline \multicolumn{8}{|l|}{ Phase 1} \\
\hline Item development & $\mathrm{X}$ & $\mathrm{X}$ & $\mathrm{X}$ & & & & \\
\hline \multicolumn{8}{|l|}{ Phase 2} \\
\hline Item selection-EFA & $\mathrm{X}$ & $\mathrm{X}$ & $\mathrm{X}$ & & & & \\
\hline Intercorrelations & $\mathrm{X}$ & $\mathrm{X}$ & $\mathrm{X}$ & $\mathrm{X}$ & $\mathrm{X}$ & $\mathrm{X}$ & $\mathrm{X}$ \\
\hline Reliabilities & $\mathrm{X}$ & $\mathrm{X}$ & $\mathrm{X}$ & $\mathrm{X}$ & $\mathrm{X}$ & $\mathrm{X}$ & $\mathrm{X}$ \\
\hline Factor structure-CFA & $\mathrm{X}$ & $\mathrm{X}$ & $\mathrm{X}$ & $\mathrm{X}$ & $\mathrm{X}$ & $\mathrm{X}$ & $\mathrm{X}$ \\
\hline \multicolumn{8}{|l|}{ Phase 3} \\
\hline Invariance & $\mathrm{X}$ & $\mathrm{X}$ & $\mathrm{X}$ & $\mathrm{X}$ & $\mathrm{X}$ & $\mathrm{X}$ & $\mathrm{X}$ \\
\hline \multicolumn{8}{|l|}{ Phase 4} \\
\hline \multicolumn{8}{|c|}{ Criterion-related and discriminant validity } \\
\hline \multicolumn{8}{|l|}{ Antecedents } \\
\hline Need satisfaction & $\mathrm{X}$ & $\mathrm{X}$ & $\mathrm{X}$ & $\mathrm{X}$ & & & $\mathrm{X}$ \\
\hline Autonomy-support & $\mathrm{X}$ & & & $\mathrm{X}$ & $\mathrm{X}$ & & \\
\hline Leadership style & $X$ & $\mathrm{X}$ & & & & & \\
\hline Job design & & $\mathrm{X}$ & & & & & \\
\hline \multicolumn{8}{|l|}{ Consequences } \\
\hline Vitality & $\mathrm{X}$ & $\mathrm{X}$ & $\mathrm{X}$ & & & & \\
\hline Emotional exhaustion & $\mathrm{X}$ & $\mathrm{X}$ & $\mathrm{X}$ & $\mathrm{X}$ & & & $\mathrm{X}$ \\
\hline Affective commitment & $\mathrm{X}$ & & & $\mathrm{X}$ & & & \\
\hline Proficiency & $\mathrm{X}$ & & & & & & $\mathrm{X}$ \\
\hline Adaptivity & $\mathrm{X}$ & & & & & & $\mathrm{X}$ \\
\hline Proactivity & $\mathrm{X}$ & & & & & & $\mathrm{X}$ \\
\hline Overall performance & $\mathrm{X}$ & & & & & & $\mathrm{X}$ \\
\hline Job effort & & & & $\mathrm{X}$ & & & \\
\hline Turnover intention & $\mathrm{X}$ & & & $\mathrm{X}$ & & & \\
\hline
\end{tabular}

is composed of four different subscales (Avolio et al., 1999): transformational leadership (20 items), contingent reward leadership (four items), active management by exception (four items), and passive leadership (eight items), answered using a 0 ("not at all") to 4 ("frequently, if not always") Likert scale. Cronbach's $\alpha$ were $.94, .70, .33$, and .86 for the French sample, and $.92, .55, .55$, and .87 for the English sample. Because reliabilities for the active management by exception subscale were very poor, results for this subscale are not reported.

Job design. The Work Design Survey (Morgeson \& Humphrey, 2006) was used in the English Canadian business student subsample. The following subscales were rated on a 1 ("strongly disagree") to 5 ("strongly agree") Likert scale: job autonomy (nine items, e.g., "The job allows me to plan how I do my work"), skill and task variety (six items, e.g., "The job involves a great deal of task variety"), task identity (four items, e.g., "The job allows me to complete work I start"), task significance (three items, e.g., "The job has a large impact on people outside the organization"), and feedback from the job and from others (six items, e.g., "The job itself provides feedback on my performance"). All items were averaged to create a job design score, with a Cronbach's $\alpha$ of .88 .
Vitality. Vitality was measured in some of the Canadian (French and English) samples using the French version (Rousseau \& Vallerand, 2003) and the English version of the vitality scale (Ryan \& Frederick, 1997; seven items, e.g., "I feel energized"), using a 1 ("do not agree at all") to 7 ("very strongly agree") response scale. Vitality was assessed in the Dutch sample using the vigour subscale from the Utrecht Work Engagement Scale (Schaufeli, Salanova, González-Romá, \& Bakker, 2002; five items, e.g., "At my work, I feel bursting with energy"). Cronbach's $\alpha$ were $.87, .88$, and .90 for the French, English, and Dutch samples, respectively.

Burnout. Burnout was measured using the emotional exhaustion subscale from the Maslach Burnout Inventory (Maslach, Jackson, \& Leiter, 1996). The validated French-Canadian version (Dion \& Tessier, 1994; four items, e.g., "I feel emotionally exhausted by my work") was used in the French-Canadian samples and the original version was used in the English-Canadian sample. The Dutch version (Schaufeli \& Van Dierendonck, 2001; five items, e.g., "I feel totally exhausted on my job") was used with the Dutch sample. The English version was translated in Mandarin for the Chinese sample. Participants indicated their level of agreement with each item to assess how they felt in the past year on a 0 ("never") to 6 ("every day") Likert scale. Cronbach's $\alpha$ was .90 in all four samples. 
Affective commitment. Affective commitment was measured using Meyer and Allen's (1997) measure of affective commitment in the Canadian (French) and Norwegian samples (6 items; e.g., "this organization has a great deal of personal meaning for me"), and was scored on a 1 (strongly disagree) to 5 (strongly agree) Likert scale. Cronbach's $\alpha$ was .85 in both samples.

Work role performance. Work role performance (defined as "the total set of performance responsibilities associated with one's employment"; Murphy \& Jackson, 1999, p. 335) was self-reported using Griffin, Neal, and Parker's (2007) scale in one of the French-Canadian subsamples and in the Chinese sample. The self-report version has been shown to have superior validity compared with a supervisor report version (Griffin et al., 2007). This scale is composed three different subscales: proficiency (e.g., fulfilling the prescribed or predictable requirements or role), adaptivity (e.g., coping with, responding to, and supporting change), and proactivity (e.g., initiating change, being self-starting, and being future-directed). These individual behaviours were measured at the individual (i.e., contributing to individual effectiveness), the team (i.e., contributing to team effectiveness), and the organization levels (i.e., contributing to organizational effectiveness), and scored on a 1 ("strongly disagree") to 5 ("strongly agree") Likert scale. In the French sample, Cronbach's $\alpha$ were .82, $.91, .93$ for proficiency, adaptivity, and proactivity subscales. In the Chinese sample, Cronbach's $\alpha$ were .85 , .89 , and .92 .

Job effort. Job effort was self-reported in the Norwegian sample with a five-item scale (Kuvaas, 2006; e.g., "I often spend extra effort in carrying out my job"), scored on a 1 ("strongly disagree") to 5 ("strongly agree") Likert scale. Cronbach's $\alpha$ was .89 .

Turnover intentions. Turnover intentions were measured in the French MBA students subsample with two items adapted from Hom and Griffeth (1991) and from Jaros (1997; e.g., "I often think about quitting this organization"). In the Norwegian sample, it was assessed with six items, three future-oriented items (e.g., "I frequently think about quitting my job") taken from O'Driscoll and Beehr (1994) and three past-oriented items (e.g., "I have pretty regular thoughts of finding a new job") taken from Luchak and Gellatly (2007). Items were scored on a 1 ("strongly disagree") to 7 ("strongly agree") Likert scale. Cronbach's $\alpha$ were .81, and .90 for the French and Norwegian samples, respectively.

Results. Correlations of the work motivation subscales with antecedents and outcomes are presented in Tables 6 and 7. Because some of the samples were large, which boosts levels of significance, we interpreted the effect sizes. To test the hypothesis that relations between antecedents, need satisfaction, work motivation, and work-related outcomes are cross-culturally equivalent, we used Cochran's Q-statistic, which provides information about the degree of homogeneity of the correlations. Though it provides a metric to evaluate whether there are differences in the size of the relations between variables, we must bear in mind that we had very few samples to conduct these analyses (between two and five per test). As samples were heterogeneous in terms of job type and organization type, statistically heterogeneous results may reflect not only cross-cultural forces, but also organizational differences, labour conditions, job types, and other uncontrolled factors.

Results generally follow the hypothesized pattern of relationships between motivation forms, antecedents, and outcomes, such that correlations go from negative with amotivation to positive with intrinsic (and vice versa for variables that are considered negative antecedents and outcomes). As hypothesized, the three psychological needs were positively related to autonomous types of motivation in all samples, though the size of their effects significantly varied across samples for competence and autonomy. The three needs were also unexpectedly positively related to introjection in three samples, though with smaller effects than with autonomous types, and they also varied significantly across samples. The needs were almost always unrelated to external regulation, and all negatively related to amotivation, but again with significant variance. Notably, results from the Chinese sample did not stand out in relation to the "Western" samples. Variation in the correlations are thus likely not due to national culture (e.g., collectivism), but from other sample differences.

As expected, autonomy support was positively related to autonomous types of motivation in all samples: its relations with intrinsic motivation were homogeneous, and slightly heterogeneous for identified regulation. Autonomy support was also unexpectedly positively related to introjection in two samples, and nonsignificantly negative in the third. It was homogeneously unrelated to external regulation, and negatively related to amotivation (with significant variance in the size of the effect). Transformational leadership was homogeneously positively related to autonomous and surprisingly also with controlled motivation (except with external regulation in the English sample) and consistently negatively related to amotivation across samples. Contingent reward leadership was homogeneously positively related to autonomous motivation, and negatively related to amotivation. The relation of contingent reward leadership to controlled motivation was significantly positive in the French sample and nonsignificantly negative in the English sample. This difference could be due to a different interpretation of contingent reward leadership across languages: contingent reward leadership often correlates with transformational leadership and emphasizes praise more than tangible rewards (Bass \& Riggio, 2006), with 
TABLE 6

Correlations between motivation with antecedents, and Q-statistics

\begin{tabular}{|c|c|c|c|c|c|c|c|c|}
\hline \multirow[b]{2}{*}{ Variable } & \multirow[b]{2}{*}{ Language } & \multirow[b]{2}{*}{$N$} & \multirow[b]{2}{*}{ Amotivation } & \multirow[b]{2}{*}{$\begin{array}{l}\text { External } \\
\text { regulation }\end{array}$} & \multicolumn{2}{|c|}{ Introjected regulation } & \multirow[b]{2}{*}{$\begin{array}{l}\text { Identified } \\
\text { regulation }\end{array}$} & \multirow[b]{2}{*}{$\begin{array}{l}\text { Intrinsic } \\
\text { motivation }\end{array}$} \\
\hline & & & & & $r$ & $\begin{array}{c}\text { Partial } \\
r\end{array}$ & & \\
\hline \multirow[t]{6}{*}{ Need for autonomy } & French & 345 & $-.34 * * *$ & .05 & $.15^{* *}$ & -.01 & $.39 * * *$ & $.47 * * *$ \\
\hline & English & 62 & $-.29 *$ & -.13 & -.08 & $-.19 *$ & .07 & $.37 * *$ \\
\hline & Dutch & 530 & $-.32 * * *$ & -.06 & $.18 * * *$ & -.03 & $.34 * * *$ & $.57 * * *$ \\
\hline & Norwegian & 856 & $-.27 * * *$ & $-.11 * * *$ & .06 & $-.10 * *$ & $.30 * * *$ & $.54 * * *$ \\
\hline & Chinese & 305 & $-.19 * *$ & -.07 & $.17 *$ & $.14 *$ & $.36^{* * *}$ & $.40 * * *$ \\
\hline & $\mathrm{Q}(4)$ & & $11.18^{*}$ & $13.19^{*}$ & $17.43 * *$ & & $15.92 * *$ & $32.51 * * *$ \\
\hline \multirow[t]{6}{*}{ Need for competence } & French & 345 & $-.18 * * *$ & $-.20 * *$ & .03 & -.04 & $.23 * * *$ & $.26^{* * *}$ \\
\hline & English & 62 & $-.31^{*}$ & -.13 & .09 & $-.17^{*}$ & .13 & $.29 *$ \\
\hline & Dutch & 530 & -.04 & .01 & $.16^{* * *}$ & .03 & $.23^{* * *}$ & $.27 * * *$ \\
\hline & Norwegian & 856 & $-.20 * * *$ & -.02 & $.16^{* * *}$ & .03 & $.27^{* * *}$ & $.33 * * *$ \\
\hline & Chinese & 305 & $-.38 * * *$ & -.06 & $.20 * * *$ & $.24 * * *$ & $.42 * * *$ & $.45 * * *$ \\
\hline & $\mathrm{Q}(4)$ & & $53.45 * * *$ & $22.15^{* * *}$ & $12.34 * *$ & & $24.27 * * *$ & $21.70 * * *$ \\
\hline \multirow[t]{6}{*}{ Need for relatedness } & French & 345 & $-.18^{* * *}$ & .10 & .10 & -.04 & $.20 * * *$ & $.31 * * *$ \\
\hline & English & 62 & -.12 & -.15 & -.08 & $-.17 *$ & .05 & $.35 * *$ \\
\hline & Dutch & 530 & $-.23 * * *$ & .01 & $.18 * * *$ & .03 & $.28 * * *$ & $.38 * * *$ \\
\hline & Norwegian & 856 & $-.28 * * *$ & -.04 & $.11 * * *$ & .00 & $.22 * * *$ & $.34 * * *$ \\
\hline & Chinese & 305 & $-.36^{* * *}$ & -.07 & $.22 * * *$ & $.16^{* *}$ & $.37 * * *$ & $.36^{* * *}$ \\
\hline & $\mathrm{Q}(4)$ & & $17.38 * *$ & $14.89^{* *}$ & $14.67 * *$ & & $21.25^{* * *}$ & 3.14 \\
\hline \multirow[t]{4}{*}{ Autonomy-support } & French & 152 & $-.26^{* *}$ & -.01 & $.18^{* *}$ & -.02 & $.35 * * *$ & $.36^{* * *}$ \\
\hline & German & 172 & -.10 & -.09 & -.09 & $-.14 *$ & $.17 *$ & $.32 * * *$ \\
\hline & Norwegian & 856 & $-.25^{* * *}$ & .04 & $.07 *$ & -.04 & $.21 * * *$ & $.39 * * *$ \\
\hline & $\mathrm{Q}(2)$ & & $7.42 *$ & 5.03 & $12.34 * *$ & & $7.25^{*}$ & 2.18 \\
\hline \multirow{3}{*}{$\begin{array}{l}\text { Transformational } \\
\text { leadership }\end{array}$} & French & 335 & $-.16^{* *}$ & $.17 * *$ & $.24 * * *$ & .05 & $.39^{* * *}$ & $.44 * * *$ \\
\hline & English & 62 & $-.33^{*}$ & -.01 & .24 & -.03 & $.43^{* * *}$ & $.50^{* * *}$ \\
\hline & $\mathrm{Q}(1)$ & & 3.35 & 3.46 & 0.00 & & 0.22 & 0.60 \\
\hline \multirow{3}{*}{$\begin{array}{l}\text { Contingent reward } \\
\text { leadership }\end{array}$} & French & 335 & -.16 & $.19 * * *$ & $.24 * * *$ & $.17 *$ & $.32 * * *$ & $.40 * * *$ \\
\hline & English & 62 & -.20 & -.02 & -.01 & $-.19 *$ & .24 & $.28^{*}$ \\
\hline & $\mathrm{Q}(1)$ & & 0.16 & $4.73^{*}$ & $6.85^{* *}$ & 0.87 & 2.17 & \\
\hline \multirow[t]{3}{*}{ Passive leadership } & French & 335 & $.15^{* *}$ & -.04 & $-.13^{*}$ & -.06 & $-.21 * * *$ & $-.31 * * *$ \\
\hline & English & 62 & $.40 * *$ & -.02 & -.10 & .04 & -.24 & -.04 \\
\hline & $\mathrm{Q}(1)$ & & $7.58 * *$ & 0.04 & 0.10 & & 0.09 & $8.47 * *$ \\
\hline Job design & English & 94 & $-.44 * * *$ & .20 & $.27 * *$ & $.16^{* *}$ & $.41 * * *$ & $.37 * * *$ \\
\hline
\end{tabular}

Degrees of freedom are shown in parenthesis for the Q-statistic. ${ }^{*} p<.05,{ }^{* *} p<.01,{ }^{* * *} p<.001$.

praise having been positively related to intrinsic motivation (Deci et al., 1999). Passive leadership was homogeneously negatively related to autonomous motivation (though less homogeneously for intrinsic motivation), unrelated to controlled motivation, and negatively related to amotivation. Job design was, as expected, positively related to autonomous motivation, less so with controlled motivation (though significantly with introjection), and negatively related to amotivation.

Among the hypothesized outcomes of work motivation, vitality was positively related to autonomous motivation, though the effects varied significantly. It was surprisingly unrelated to controlled motivation (though there was one small positive relation with introjection), and negatively related to amotivation, again with variance. The opposite pattern was found for emotional exhaustion. There was variance in correlations with intrinsic motivation, though all were in the expected direction. Affective commitment was positively related to autonomous motivation, with significant variance. It was unexpectedly positively related to controlled motivation (though with smaller effects), and negatively related to amotivation. Self-reported job effort was also positively related to autonomous motivation, as it was with introjected regulation. It was weakly positively related to external regulation (though it was significant due to the large sample size), and negatively to amotivation. Finally, turnover intentions were negatively related to autonomous motivation, unrelated to controlled motivation (though one correlation was positive), and positively related to amotivation as expected (with significant variance for all subscales).

Self-reported performance, regardless of type, was always positively related to identified regulation. The variance in these relations, though significant, was not large. Intrinsic motivation was also positively related to all three types of performance, but with more variability. In particular for the French sample, correlations with intrinsic motivation were weaker and even nonsignificant in the case of proactive performance, supporting the 
TABLE 7

Correlations between motivation with outcomes, and Q-statistics

\begin{tabular}{|c|c|c|c|c|c|c|c|c|}
\hline \multirow[b]{2}{*}{ Variable } & \multirow[b]{2}{*}{ Language } & \multirow[b]{2}{*}{$N$} & \multirow[b]{2}{*}{ Amotivation } & \multirow[b]{2}{*}{ External regulation } & \multicolumn{2}{|c|}{ Introjected regulation } & \multirow[b]{2}{*}{ Identified regulation } & \multirow[b]{2}{*}{ Intrinsic motivation } \\
\hline & & & & & $r$ & Partial $r$ & & \\
\hline \multirow[t]{4}{*}{ Vitality } & French & 241 & $-.30 * * *$ & -.01 & .06 & $-.10^{*}$ & $.35 * * *$ & $.46^{* * *}$ \\
\hline & English & 62 & $-.46^{* * *}$ & -.05 & .23 & $-.26^{*}$ & $.60 * * *$ & $.65 * * *$ \\
\hline & Dutch & 530 & $-.16^{* * *}$ & -.05 & $.19^{* * *}$ & -.02 & $.35 * * *$ & $.46^{* * *}$ \\
\hline & $\mathrm{Q}(2)$ & & $16.76^{* * *}$ & 0.54 & $6.61 *$ & & $12.33 * *$ & $9.20^{*}$ \\
\hline \multirow[t]{5}{*}{ Emotional exhaustion } & French & 380 & $.22 * * *$ & .10 & .04 & .07 & $-.17 * *$ & $-.30 * * *$ \\
\hline & English & 62 & $.32 *$ & -.02 & -.01 & .12 & -.16 & $-.40 * *$ \\
\hline & Dutch & 530 & $.26^{* * *}$ & $.14 * * *$ & $-.09 *$ & .03 & $-.19^{* * *}$ & $-.37 * * *$ \\
\hline & Chinese & 305 & $.32 * * *$ & $.14^{*}$ & -.05 & $.16^{* *}$ & $-.19 * * *$ & $-.19 * * *$ \\
\hline & $\mathrm{Q}(3)$ & & 4.50 & 3.45 & 7.68 & & 0.31 & $16.98 * * *$ \\
\hline \multirow[t]{3}{*}{ Affective commitment } & French & 505 & $-.37 * * *$ & $.14^{* *}$ & $.26^{* * *}$ & -.14 & $.49 * * *$ & $.51 * * *$ \\
\hline & Norwegian & 856 & -.04 & $.11^{* *}$ & $.12 * * *$ & -.02 & $.28 * * *$ & $.35 * * *$ \\
\hline & $\mathrm{Q}(1)$ & & $77.40 * * *$ & 0.59 & $13.59 * * *$ & & $41.50 * * *$ & $26.75 * * *$ \\
\hline \multirow[t]{3}{*}{ Proficiency } & French & 139 & $-.26^{* * *}$ & $.37 * * *$ & $.29 * * *$ & $.12 *$ & $.33 * * *$ & $.26 * * *$ \\
\hline & Chinese & 305 & $-.35^{* * *}$ & .06 & $.25^{* * *}$ & $.20 * *$ & $.46^{* * *}$ & $.42 * * *$ \\
\hline & $\mathrm{Q}(1)$ & & 2.01 & $20.46^{* * *}$ & 0.35 & & $5.04 *$ & $6.78 * *$ \\
\hline \multirow[t]{3}{*}{ Adaptivity } & French & 139 & $-.19 *$ & .07 & .13 & -.01 & $.31 * * *$ & $.17^{*}$ \\
\hline & Chinese & 305 & $-.25 * * *$ & .06 & $.27 * * *$ & $.18 * *$ & $.43 * * *$ & $.46 * * *$ \\
\hline & $\mathrm{Q}(1)$ & & 0.79 & 0.02 & $4.18^{*}$ & & $4.05^{*}$ & $21.64 * * *$ \\
\hline \multirow[t]{3}{*}{ Proactivity } & French & 139 & -.11 & $.20^{*}$ & $.29 * * *$ & -.01 & $.27 * *$ & .14 \\
\hline & Chinese & 305 & -.09 & .03 & $.23 * * *$ & .09 & $.42 * * *$ & $.48 * * *$ \\
\hline & $\mathrm{Q}(1)$ & & 0.08 & $5.64 *$ & 0.79 & & $6.02 *$ & $27.76^{* * *}$ \\
\hline Job effort & Norwegian & 856 & $-.34 * * *$ & $.02 * * *$ & $.34 * * *$ & $.15^{* *}$ & $.48 * * *$ & $.45^{* * *}$ \\
\hline \multirow[t]{3}{*}{ Turnover intention } & French & 202 & $.37 * * *$ & $.17^{*}$ & -.12 & .09 & $-.38 * * *$ & $-.47 * * *$ \\
\hline & Norwegian & 856 & $.19 * * *$ & .05 & .05 & $.10^{*}$ & $-.09 * *$ & $-.23 * * *$ \\
\hline & $\mathrm{Q}(1)$ & & $12.67 * * *$ & $4.80^{*}$ & $9.44 * *$ & & $31.13 * * *$ & $25.31 * * *$ \\
\hline
\end{tabular}

Degrees of freedom are shown in parenthesis for the Q-statistic. ${ }^{*} p<.05,{ }^{* *} p<.01,{ }^{* * *} p<.001$.

assumption that identified motivation is likely to be more strongly related to performance than intrinsic motivation, especially when work involves having to engage in less interesting tasks (Gagné \& Deci, 2005). The French sample used in this case consisted of bureaucrats working for a government agency, who perhaps found their work less interesting or stimulating. In the same sample, we also found that proficiency and proactivity were unexpectedly positively related to controlled motivation, whereas adaptivity was not. Still, correlations between performance and controlled motivation were smaller than the ones with autonomous motivation. Proficiency and adaptivity were homogeneously negatively related to amotivation, whereas proactivity was unrelated.

Although the pattern of correlations between the different regulatory styles and both outcomes and antecedents generally followed a typical pattern, with correlations becoming increasingly positive or increasingly negative as one moves along the different subtypes, the positive associations between introjected regulation and several variables stand out. Because these associations might be due to the shared variance with identified regulation, we ran a series of additional partial correlations to examine whether introjected regulation would still relate strongly to both outcomes and antecedents while partially out its shared variance with identified regulation. In Tables 6 and 7, the second coefficient in the column for introjected regulation is the partial correlation between introjected regulation and measured outcomes, when controlling for identified regulation. As can be noticed, several of the observed significant correlations between introjection and measured variables became more in line with our hypotheses, for 14 out of 25 correlations with antecedents, and for 11 out of 18 correlations with outcomes. This suggests that the observed associations between introjected regulation and other variables are in many cases spurious.

\section{DISCUSSION}

The present research developed and tested a new measure of work motivation, the Multidimensional Work Motivation Scale (MWMS), based on the multidimensional conceptualization of motivation offered by selfdetermination theory. It tested for the reliability, factorial structure, and validity of this new scale across seven languages and nine different countries varying in their culture. As SDT-based organizational research is on the rise (see for recent examples Grant \& Berry, 2011; Greguras \& Diefendorff, 2007; Liu \& Fu, 2011; van Beek, Hu, Schaufeli, Taris, \& Schreurs, 2011; Van den 
Broeck, Lens, De Witte, \& Van Coillie, 2013), there is a growing need for a scale like the MWMS to foster future research that will continue to rigorously and accurately assess relations between the different types of motivation and organizationally relevant variables.

The MWMS improves over similar work motivation scales in several ways. First, evidence for its factorial validity exists for seven languages across nine different country samples. The German version of the scale was the least invariant of all languages, but still showed a good fit to the basic factor structure and displayed expected relations with outcomes. The problem in this version seemed to lie with the introjection subscale, for which other problems have been pointed out (Assor et al., 2009). Operationalizations for introjected regulation, as will be discussed later, may therefore require additional investigation. Interestingly, the languages for which the factor loadings were found to vary were not necessarily languages that were from different language families as those for which factor loadings were invariant. Though it would be better if the MWMS were completely invariant across languages, we know of no other validated scales meeting this criterion across such a large number of languages and for a factor structure as complex as the MWMS (e.g., Gagné et al., 2010; Schaufeli, Bakker, \& Salanova, 2006). The MWMS also emphasizes the theorized contingency imbedded in the definition of controlled motivation more strongly than previous scales through a change in the stem question, which now focuses on reasons for putting efforts at work. Finally, it balances out approach and avoidance motivation in order to avoid confounding motivational constructs, as other scales have been criticized for (Assor et al., 2009). Finally, the external regulation subscale includes material and social rewards and punishments, a balance that has never been considered in previous scales and that could be used to study the differential effects of these different types of contingencies in future research. These additional features offer unique opportunities to steer research into new directions.

Depending on the research question, scholars can use the subscales of the MWMS separately to examine their discrete effects (Koestner \& Losier, 2002), or can aggregate them into autonomous and controlled types to simplify analyses. This technique and the use of personlevel approaches, such as the use of cluster analysis or latent profile analysis (e.g., Van den Broeck et al., 2013), is advised over using the relative autonomy index (Grolnick \& Ryan, 1987), which consists of subtracting controlled motivation from autonomous motivation. The use of difference scores has been heavily criticized in psychology and management for masking the effects of their respective variables or unduly attributing results to them (Edwards, 2001; Johns, 1981; Judge, Bono, Erez, \& Locke, 2005).

We found that motivation type matters in all of the cultures and organizational contexts examined here: some types of motivation do not yield the same outcomes as other types of motivation. The motivation subscales were related mostly in expected directions with known and hypothesized antecedents and outcomes that are relevant to the domain of organizational psychology. Autonomous types of motivation were positively related to the satisfaction of the psychological needs for autonomy, competence, and relatedness, as well as with job design, autonomy-support, and managerial leadership (especially transformational). Controlled motivation types were unrelated to need satisfaction and autonomy support, but were related to other types of more or less supportive and controlling leadership behaviours. However, we found that introjected regulation was often positively related to good outcomes, albeit less strongly than with autonomous types of motivation. Controlling for its adjacent autonomous motivation type, identified regulation, many of these relations disappeared. More research on introjected regulation should be conducted to uncover whether this is a function of how introjection is operationalized in SDT-based measures, and whether one should split its approach and avoidance components. As with recent research on organizational commitment, perhaps introjected regulation would yield different results depending on how it is paired with other forms of motivation (e.g., external regulation versus more autonomous forms of motivation). Normative commitment has been shown to lead to different outcomes depending on whether it is paired with continuance or with affective commitment (Gellatly, Meyer, \& Luchak, 2006). As suggested earlier, the use of motivational profiles as an alternative to considering the types of motivation as unrelated variables may shed some new light in this matter. Amotivation was negatively related to need satisfaction, autonomy support, and transformational leadership, and was positively related to passive leadership, which is consistent with the idea that it reflects some helplessness and meaninglessness (Legault, Green-Demers, \& Pelletier, 2006). Though these effects sometimes varied across samples, they were mostly in the expected directions. Future research could evaluate if the strength of these relations may be moderated by cultural, organizational, or job factors.

Autonomous motivation was also positively related to important outcomes, such as vitality, emotional exhaustion, affective commitment, performance, personal initiative, effort and turnover intentions. Notably in the French sample, and in support of Gagné and Deci (2005), performance was more highly correlated to identified than to intrinsic motivation. This is not surprising in the work context, as many tasks that must be done in many jobs are not inherently interesting (Fernet et al., 2008; Koestner \& Losier, 2002). This suggests that it may be more practical for the organization to promote the internalization of the value of the task (i.e., promoting identified regulation), rather than trying to make the tasks more fun (i.e., promoting intrinsic motivation). The 
results also show that autonomous motivation is as important for proficiency as it is for adaptivity and proactivity at work. This provides evidence for the suggestion that proficiency cannot be equated with work simplicity (Griffin et al., 2007). Instead, proficiency is defined as doing one's core job tasks correctly, no matter how complex the tasks are. For example, a physician's core tasks are far from simple, and thus performance of these core tasks should be highly related to autonomous work motivation. Moreover, recent research on task prototypicality shows that the performance of nonprototypical tasks requires higher levels of autonomous work motivation compared to prototypical tasks, which seem to be invariably autonomously motivated (therefore creating a ceiling effect, which causes nonsignificant effects; Adriasola, Unsworth, \& Day, 2012). This could happen because what attracts people to a profession or job may be what is prototypical about it, thereby creating a basic (ceiling) level of autonomous work motivation for these particular tasks. This example shows how complex the concept of work performance is, and how important it is to take into consideration this complexity if we want to develop a better understanding of the role work motivation plays in promoting performance.

The criterion validity of the MWMS appears to be superior to the criterion validity of other work motivation scales based on SDT, possibly because of the aforementioned changes brought through this new scale. For example, Gagné et al.'s (2010) external and introjected regulation measures were more highly related to satisfaction of the need for autonomy (which should not be the case) than were the equivalent MWMS subscales. This may indicate that the MWMS more successfully captures the theorized contingency between behaviour and outcomes within the controlled motivation subscales. Previous scales (e.g., Gagné et al., 2010; Tremblay et al., 2009) also failed to show that turnover intentions were positively related to external regulation and highly negatively related to autonomous forms of motivation, as we had hypothesized and found with the MWMS subscale. Finally, affective commitment was more highly related to introjected and identified regulation in these previous scales than in the MWMS. Though we would expect affective commitment to relate positively to identified regulation, this should not be the case for introjected regulation (Gagné et al., 2008). Finally, emotional exhaustion also showed stronger negative relations with the MWMS autonomous motivation subscales than with Blais et al.'s (1993) subscales.

Though not explicitly stated in any writing, we often assume that self-determination theory would predict negative relations between controlled types of motivation and outcomes. Instead, most of the research (Chemolli, Gagné, \& Koestner, 2012), including the present study, shows that external regulation is not highly related to any of the antecedents and outcomes that are typically related to autonomous forms of motivation, and that introjected regulation is often positively related to them, albeit with smaller effect sizes. This is counterintuitive, given that many human resource practices focus on increasing external regulation through performance monitoring and pay-for performance compensation systems (Gagné \& Bhave, 2010; Gagné \& Forest, 2008). More research on controlled forms of motivation is needed to assess their impact on other behaviours, perhaps unwanted ones, such as deviant and unethical behaviours.

\section{Strengths and limitations}

This research has several strengths, including the careful creation and selection of items, stringent invariance analyses, and complex sampling. Indeed, data gathered to validate the MWMS were obtained in seven languages across nine countries varying widely in their cultural values and economic systems, and across a wide variety of organizations and jobs. This heterogeneity offers some confidence to claim that the MWMS is equally applicable across these different languages, countries, and organizational contexts. Offering researchers a cross-culturally validated scale will allow them to conduct stringent research on cross-cultural similarities and differences in motivational processes in work environments.

This research also has limitations, the first one being that all data were collected cross-sectionally using selfreports, which could lead to common method variance (CMV) issues. However, in this study not all correlations were statistically significant, despite some large samples. This indicates that the relationships found are less likely to be spurious (Spector, 2006). An additional CFA in the French, English, and Dutch sample, adding a common factor, showed a slight increase in fit, but only very small changes to factor loadings (cf. Johnson, Rosen, \& Djurdjevic, 2011), which indicates no serious CMV problems in the factorial structure of the scale. Though the social desirability of the MWMS was not assessed, data from similar scales, such as the Blais et al. (1993) scale, found very low relations between the SDT-based motivation scales and the Marlowe-Crowne scale.

Another limitation is that the MWMS does not include an integrated regulation subscale, which is a form of extrinsic motivation that is more fully internalized than identified regulation. First, this is because previously published scales that contain an integration subscale typically show that it can hardly be statistically separated from identified and intrinsic motivation subscales (Mallett, Kawabata, Newcombe, Otero-Forero, \& Jackson, 2007; Tremblay et al., 2009; Vallerand et al., 1992). Our first round of data analysis included nine possible integration items, but, because they showed the same factorial problems, they were dropped. Second, to date no research has demonstrated that integration accounts for additional variance in outcomes 
after including identified or intrinsic motivation. This brought us to question the value of adding an integrated regulation subscale to the MWMS, since it would lengthen the measure with no apparent benefits. Third, items that measure integrated motivation in other scales are questionable in terms of their face value. They often resemble items that measure passion towards an activity (e.g., "Because it has become a fundamental part of who I am"; Tremblay et al., 2009). Passion explicitly measures simultaneously people's "social identity" to the activity and their motivation for it (Vallerand et al., 2003), and therefore differs from "mere" motivation.

As very little self-determination theory research has examined individual differences that might influence need satisfaction and the development of work motivation, future research could focus on examining such traits as causality orientations (Deci \& Ryan, 1985b), and more classic personality traits such as the HEXACO (Lee \& Ashton, 2004), which may colour people's interpretations of, and reactions to, work-relevant events. For example, Gagné et al. (2010) found that trait optimism was positively related to autonomous but not to controlled forms of motivation. Researchers could also study other situational factors, such as team cohesion and compensation systems (Gagné \& Forest, 2008), and test how manipulations of motivation would yield different motivational scores on the MWMS. Finally, the MWMS offers the opportunity for future research to examine potential differential antecedents and outcomes of social versus material external regulation. As past research has shown that tangible rewards may have more debilitating effects on intrinsic motivation than praise (a social reward; Deci et al., 1999), it would be interesting to examine this issue in the work domain.

\section{CONCLUSION}

As businesses and organizations are globalizing, researchers and practitioners must find ways to help managers and organizations engage diverse employees. To accomplish this, they must understand how to this can be achieved. Self-determination theory offers a framework that is cross-culturally valid, and which shows that employees who feel autonomous, competent, and related to others are more likely to be truly engaged no matter what their background is (Meyer \& Gagné, 2008). We hope the MWMS will help the proliferation of organizational research that uses the SDT framework, which has yielded very useful results in other fields (Deci \& Ryan, 2008).

\section{REFERENCES}

Adriasola, E., Unsworth, K. L., \& Day, D. V. (2012, August). Goal selfconcordance: Understanding its effects through a new conceptualization \& task differentiation. Paper presented at the Academy of Management Conference, Boston, MA.
Assor, A., Vansteenkiste, M., \& Kaplan, A. (2009). Identified vs introjected approach and introjected avoidance motivations in school and in sports: The limited benefits of self-worth strivings. Journal of Educational Psychology, 101, 482-497. doi:10.1037/ a0014236

Avolio, B. J., Bass, B. M., \& Jung, D. I. (1999). Re-examining the components of transformational and transactional leadership using the Multifactor Leadership Questionnaire. Journal of Occupational and Organizational Psychology, 72, 441-462. doi:10.1348/ 096317999166789

Baard, P. P., Deci, E. L., \& Ryan, R. M. (2004). Intrinsic need satisfaction: A motivational basis of performance and well-being in two work settings. Journal of Applied Social Psychology, 34, 20452068. doi:10.1111/j.1559-1816.2004.tb02690.x

Bass, B. M., \& Avolio, B. J. (1989). The multifactor leadership questionnaire. Palo Alto, CA: Consulting Psychologists Press.

Bass, B. M., \& Riggio, R. E. (2006). Transformational leadership (2nd ed.). Mahwah, NJ: Lawrence Erlbaum Associates.

Blais, M. R., Brière, N. M., Lachance, L., Riddle, A. S., \& Vallerand, R. J. (1993). L'inventaire des motivations au travail de Blais [Blais's work motivation inventory]. Revue Québécoise De Psychologie, 14, 185-215. doi:10.1037//0033-2909.107.2.238

Byrne, B. M. (2006). Structural equation modelling with eqs: Basic concepts, applications, and programming. Mahwah, NJ: Lawrence Erlbaum.

Chemolli, E., Gagné, M., \& Koestner, R. (2012, June). Recurring null results between extrinsic motivation and performance and wellbeing in the workplace: Finding meaning in the void. Paper presented at the Institute of Work Psychology Conference, Sheffield.

Cheung, G. W., \& Rensvold, R. B. (2002). Evaluating goodness-of-fit indexes for testing measurement invariance. Structural Equation Modelling, 9, 233-255. doi:10.1207/S15328007SEM0902_5

Chirkov, V. I., \& Ryan, R. M. (2001). Parent and teacher autonomysupport in Russian and U.S. adolescents: Common effects on wellbeing and academic motivation. Journal of Cross Cultural Psychology, 32, 618-635. doi:10.1177/0022022101032005006

Chirkov, V. I., Ryan, R. M., Kim, Y., \& Kaplan, U. (2003). Differentiating autonomy from individualism and independence: A self-determination theory perspective on internalization of cultural orientations and well-being. Journal of Personality and Social Psychology, 84, 97-110. doi:10.1037/0022-3514.84.1.97

De Cooman, R., De Gieter, S., Pepermans, R., Jegers, M., \& Van Acker, F. (2009). Development and validation of the Work Effort Scale. European Journal of Psychological Assessment, 25, 266273. doi:10.1027/1015-5759.25.4.266

Deci, E. L., Koestner, R., \& Ryan, R. M. (1999). A meta-analytic review of experiments examining the effects of extrinsic rewards on intrinsic motivation. Psychological Bulletin, 125, 627-668. doi:10.1037//0033-2909.125.6.627

Deci, E. L., \& Ryan, R. M. (1985a). Intrinsic motivation and selfdetermination in human behaviour. New York, NY: Plenum.

Deci, E. L., \& Ryan, R. M. (1985b). The general causality orientations scale: Self-determination in personality. Journal of Research in Personality, 19, 109-134. doi:10.1016/0092-6566(85)90023-6

Deci, E. L., \& Ryan, R. M. (2000). The "what" and "why" of goal pursuits: Human needs and the self-determination of behaviour. Psychological Inquiry, 11, 227-268. doi:10.1207/S15327965PLI1104_01

Deci, E. L., \& Ryan, R. M. (2008). Facilitating optimal motivation and psychological well-being across life's domains. Canadian Psychology, 49, 14-23. doi:10.1037/0708-5591.49.1.14

Deci, E. L., Ryan, R. M., Gagné, M., Leone, D. L., Usunov, J., \& Kornazheva, B. P. (2001). Need satisfaction, motivation and wellbeing in the work organizations of a former eastern bloc country: A cross-cultural study of self-determination. Personality and Social Psychology Bulletin, 27, 930-942. doi:10.1177/0146167201278002

Dion, G., \& Tessier, R. (1994). Validation de la traduction de l'inventaire d'epuisement professionnel de Maslach et Jackson [Validation of the translation of the Maslach and Jackson burnout scale]. 
Canadian Journal of Behavioural Science, 26, 210-227. doi:10.1037/0008-400X.26.2.210

Edwards, J. R. (2001). Ten difference score myths. Organizational Research Methods, 4, 265-287. doi:10.1177/109442810143005

Farkas, M. S., \& Grolnick, W. S. (2010). Examining the components and concomitants of parental structure in the academic domain. Motivation and Emotion, 34, 266-279. doi:10.1007/s11031-010-9176-7

Fernet, C., Gagné, M., \& Austin, S. (2010). How do work motivation and social support predict job burnout over time? Journal of Organizational Behaviour, 31, 1163-1180. doi:10.1002/job.673

Fernet, C., Senécal, C., Guay, F., Marsh, H., \& Dowson, M. (2008). The work tasks motivation scale for teachers (WTMST). Journal of Career Assessment, 16, 256-279. doi:10.1177/1069072707305764

Gagné, M. (2003). The role of autonomy support and autonomy orientation in prosocial behaviour engagement. Motivation and Emotion, 27, 199-223. doi:10.1023/A:1025007614869

Gagné, M., \& Bhave, D. (2010). Autonomy in the workplace: An essential ingredient to employee engagement and well-being. In V. Chirkov, R. M. Ryan, \& K. M. Sheldon (Eds.), Handbook of autonomy in cross-cultural context (pp. 163-190). New York, NY: Springer.

Gagné, M., Chemolli, E., Forest, J., \& Koestner, R. (2008). The temporal relations between work motivation and organizational commitment. Psychologica Belgica, 48, 219-241. doi:10.5334/pb48-2-3-219

Gagné, M., \& Deci, E. L. (2005). Self-determination theory and work motivation. Journal of Organizational Behaviour, 26, 331-362. doi:10.1002/job.322

Gagné, M., \& Forest, J. (2008). The study of compensation systems through the lens of self-determination theory: Reconciling 35 years of debate. Canadian Psychology, 49, 225-232. doi:10.1037/ a0012757

Gagné, M., Forest, J., Gilbert, M.-H., Aubé, C., Morin, E., \& Malorni, A. (2010). The Motivation at Work Scale: Validation evidence in two languages. Educational and Psychological Measurement, 70, 628-646. doi:10.1177/0013164409355698

Gellatly, I. R., Meyer, J. P., \& Luchak, A. A. (2006). Combined effects of the three commitment components on focal and discretionary behaviours: A test of Meyer and Herscovitch's propositions. Journal of Vocational Behaviour, 69, 331-345. doi:10.1016/j. jvb.2005.12.005

Grant, A. M., \& Berry, J. (2011). The necessity of others is the mother of invention: Intrinsic and prosocial motivations, perspective-taking, and creativity. Academy of Management Journal, 54, 73-96. doi:10.5465/AMJ.2011.59215085

Greguras, G. J., \& Diefendorff, J. M. (2007). Different fits satisfy different needs: Linking person-environment fit to employee commitment and performance using self-determination theory. Journal of Applied Psychology, 94, 465-477. doi:10.1037/a0014068

Griffin, M. A., Neal, A., \& Parker, S. K. (2007). A new model of work role performance: Positive behaviour in uncertain and interdependent contexts. Academy of Management Journal, 50, 327-347. doi:10.5465/AMJ.2007.24634438

Grolnick, W. S., \& Ryan, R. M. (1987). Autonomy in children's learning: An experimental and individual differences investigation. Journal of Personality and Social Psychology, 52, 890-898. doi:10.5465/AMJ.2007.24634438

Grouzet, F. M., Kasser, T., Ahuvia, A., Dols, J. M. F., Kim, Y., Lau, S., ... Sheldon, K. M. (2005). The structure of goals across 15 cultures. Journal of Personality and Social Psychology, 89, 800-816. doi:10.1037/0022-3514.89.5.800

Guay, F., Vallerand, R. J., \& Blanchard, C. (2000). On the assessment of situational intrinsic and extrinsic motivation: The situational motivation scale. Motivation and Emotion, 24, 175-213. doi:10.1023/A:1005614228250

Hofstede, G. (2001). Culture's consequences: Comparing values, behaviours, institutions, and organizations across nations (2nd ed.). Thousand Oaks, CA: Sage Publications.
Hom, P. W., \& Griffeth, R. W. (1991). Structural equations modelling test of a turnover theory: Cross-sectional and longitudinal analyses. Journal of Applied Psychology, 76, 350-366. doi:10.1037/00219010.76.3.350

Jaros, S. J. (1997). An assessment of Meyer and Allen's (1991) threecomponent model of organizational commitment and turnover intentions. Journal of Vocational Behaviour, 51, 319-337. doi:10.1006/jvbe.1995.1553

Johns, G. (1981). Difference score measures of organizational behavior variables: A critique. Organization Behavior and Human Performance, 27, 443-463. doi:10.1016/0030-5073(81)90033-7

Johnson, R. E., Rosen, C. C., \& Djurdjevic, E. (2011). Assessing the impact of common method variance on higher-order multidimensional constructs. Journal of Applied Psychology, 96, 744-761. doi:10.1037/a0021504

Judge, T. A., Bono, J. E., Erez, A., \& Locke, E. A. (2005). Core selfevaluations and job and life satisfaction: The role of self-concordance and goal attainment. Journal of Applied Psychology, 90, 257-268. doi:10.1037/0021-9010.90.2.257

Kline, R. B. (2005). Principles and practice of structural equation modelling (2nd ed.). New York, NY: Guilford Press.

Koestner, R., \& Losier, G. F. (2002). Distinguishing three ways of being internally motivated: A closer look at introjection, identification, and intrinsic motivation. In E. L. Deci \& R. M. Ryan (Eds.), Handbook of self-determination research (pp. 101-121). Rochester, NY: University of Rochester Press.

Koestner, R., Losier, G. F., Vallerand, R. J., \& Carducci, D. (1996). Identified and introjected forms of political internalization: Extending self-determination theory. Journal of Personality and Social Psychology, 70, 1025-1036. doi:10.1037//00223514.70.5.1025

Kuvaas, B. (2006). Work performance, affective commitment, and work motivation: The roles of pay administration and pay level. Journal of Organizational Behaviour, 27, 365-385. doi:10.1002/job.377

Lee, K., \& Ashton, M. C. (2004). Psychmetric properties of the HEXACO personality inventory. Multivariate Behavioural Research, 39, 329-358. doi:10.1207/s15327906mbr3902_8

Legault, L., Green-Demers, I., \& Pelletier, L. G. (2006). Why do high school students lack motivation in the classroom? Towards an understanding of academic motivation and social support. Journal of Educational Psychology, 98, 567-582. doi:10.1037/00220663.98.3.567

Liu, D., \& Fu, P.-P. (2011). Motivating protégé's personal learning in teams: A multilevel investigation of autonomy support and autonomy orientation. Journal of Applied Psychology, 96, 1195-1208. doi: $10.1037 / \mathrm{a} 0024716$

Luchak, A. A., \& Gellatly, I. R. (2007). A comparison of linear and nonlinear relations between organizational commitment and work outcomes. Journal of Applied Psychology, 92, 786-793. doi:10.1037/0021-9010.92.3.786

Mallett, C., Kawabata, M., Newcombe, P., Otero-Forero, A., \& Jackson, S. (2007). Sport motivation scale-6 (SMS-6): A revised six-factor sport motivation scale. Psychology of Sport and Exercise, 8, 600-614. doi:10.1016/j.psychsport.2006.12.005

Maslach, C., Jackson, S. E., \& Leiter, M. P. (1996). Maslach burnout inventory manual. Palo Alto, CA: Consulting Psychology Press.

Meyer, J. P., \& Allen, N. J. (1997). Commitment in the workplace: Theory, research, and application. Thousand Oaks, CA: Sage Publishing.

Meyer, J. P., \& Gagné, M. (2008). Employee engagement from a selfdetermination theory perspective. Industrial and Organizational Psychology, 1, 60-62. doi:10.1111/j.1754-9434.2007.00010.x

Moreau, E., \& Mageau, G. A. (2012). The importance of perceived autonomy support for the psychological health and work satisfaction of health professionals: Not only supervisors count, colleagues too!. Motivation and Emotion, 36, 268-286. doi:10.1007/s11031-011-9250-9

Morgeson, F. P., \& Humphrey, S. E. (2006). The work design questionnaire (WDQ): Developing and validating a comprehensive measure 
for assessing job design and the nature of work. Journal of Applied Psychology, 91, 1321-1339. doi:10.1037/0021-9010.91.6.1321

Murphy, P. R., \& Jackson, S. E. (1999). Managing work-role performance: Challenges for 21 st century organizations and employees. In D. R. Ilgen \& E. D. Pulakos (Eds.), The changing nature of work performance (pp. 325-365). San Francisco, CA: Jossey-Bass.

O‘Driscoll, M. P., \& Beehr, T. A. (1994). Supervisor behaviours, role stressors and uncertainty as predictors of personal outcomes for subordinates. Journal of Organizational Behaviour, 15, 141-155. doi:10.1002/job.4030150204

Parker, S. K., \& Ohly, S. (2008). Designing motivating jobs. In R. Kanfer, G. Chen, \& R. Pritchard (Eds.), Work motivation: Past, present and future. New York, NY: Psychology Press.

Pelletier, L. G., Fortier, M. S., Vallerand, R. J., Tuson, K. M., Brière, N. M., \& Blais, M. R. (1995). Towards a new measure of intrinsic motivation, extrinsic motivation, and amotivation in sports: The sport motivation scale (SMS). Journal of Sport \& Exercise Psychology, 17, 35-53.

Pelletier, L. G., Tuson, K. M., Green-Demers, I., Noels, K., \& Beaton, A. M. (1998). Why are you doing things for the environment? The motivation towards the environment scale (mtes). Journal of Applied Social Psychology, 28, 437-468. doi:10.1111/j.15591816.1998.tb01714.x

Rotter, J. B. (1954). Social learning and clinical psychology. New York, NY: Prentice-Hall.

Rousseau, F. L., \& Vallerand, R. J. (2003). Le rôle de la passion dans le bien-être subjectif des aînés [The role of passion in the psychological well-being of the elderly]. Revue Québécoise De Psychologie, $24,197-211$.

Ryan, R. M., \& Connell, J. P. (1989). Perceived locus of causality and internalization: Examining reasons for acting in two domains. Journal of Personality and Social Psychology, 57, 749-761. doi:10.1037/0022-3514.57.5.749

Ryan, R. M., \& Frederick, C. M. (1997). On energy, personality and health: Subjective vitality as a dynamic reflection of well-being. Journal of Personality, 65, 529-565. doi:10.1111/j.1467-6494.1997. tb00326.x

Schaufeli, W. B., Bakker, A. B., \& Salanova, M. (2006). The measurement of work engagement with a short questionnaire: A crossnational study. Educational and Psychological Measurement, 66, 701-716. doi:10.1177/0013164405282471

Schaufeli, W. B., Salanova, M., González-Romá, V., \& Bakker, A. B. (2002). The measurement of engagement and burnout: A two sample confirmatory factor analytic approach. Journal of Happiness Studies, 3, 71-92. doi:10.1023/A:1015630930326

Schaufeli, W. B., \& Van Dierendonck, D. (2001). Utrechtse Burnout Schaal (UBOS) [The Utrecht Burout Scale (UBOS)]. De Psycholoog, 36, 9-12. doi:10.1037//1076-8998.6.1.43

Sheldon, K. M., Elliot, A. J., Ryan, R. M., Chirkov, V. I., Kim, Y., Wu, C., ... Sun, Z. (2004). Self-concordance and subjective well-being in four cultures. Journal of Cross-Cultural Psychology, 35, 209223. doi: $10.1177 / 0022022103262245$

Spector, P. E. (2006). Method variance in organizational research. Organizational Research Methods, 9, 221-232. doi:10.1177/ 1094428105284955

Stajkovic, A. D., \& Luthans, F. (1997). A meta-analysis of the effects of organizational behaviour modification on task performance, 1975-1995. Academy of Management Journal, 5, 1122-1149. doi: $10.2307 / 256929$
Steers, R. M., Mowday, R. T., \& Shapiro, D. L. (2004). The future of work motivation theory. Academy of Management Review, 29, 379387. doi:10.5465/AMR.2004.13670978

Tremblay, M. A., Blanchard, C. M., Taylor, S., Pelletier, L. G., \& Villeneuve, M. (2009). Work extrinsic and intrinsic motivation scale: Its value for organizational psychology research. Canadian Journal of Behavioural Science, 41, 213-226. doi:10.1037/a0015167

Vallerand, R. J. (1997). Towards a hierarchical model of intrinsic and extrinsic motivation. In M. P. Zanna (Ed.), Advances in experimental social psychology (Vol. 29, pp. 271-360). San Diego, CA: Academic Press.

Vallerand, R. J., Blanchard, C. B., Mageau, G. A., Koestner, R., Ratelle, C., Léonard, M., ... Marsolais, J. (2003). Les passions de l'âme: On obsessive and harmonious passion. Journal of Personality and Social Psychology, 85, 756-767. doi:10.1037/0022-3514.85.4.756

Vallerand, R. J., Pelletier, L. G., Blais, M. R., Brière, N. M., Sénécal, C., \& Vallières, E. F. (1992). The academic motivation scale: A measure of intrinsic, extrinsic, and amotivation in education. Educational and Psychological Measurement, 52, 1003-1017. doi:10.1177/0013164492052004025

van Beek, I., Hu, Q., Schaufeli, W. B., Taris, T. W., \& Schreurs, B. H. J. (2011). For fun, love or money: What drives workaholic, engaged and burned-out employees at work? Applied Psychology: An International Review, 61, 30-55. doi:10.1111/j.1464-0597.2011.00454.x

Van den Broeck, A., Lens, W., De Witte, H., \& Van Coillie, H. (2013). Unravelling the importance of the quantity and the quality of workers' motivation for well-being: A person-centered perspective. Journal of Vocational Behaviour, 82, 69-78. doi:10.1016/j. jvb.2012.11.005

Van den Broeck, A., Vansteenkiste, M., De Witte, H., Soenens, B., \& Lens, W. (2010). Capturing autonomy, competence, and relatedness at work: Construction and initial validation of the work-related basic need satisfaction scale. Journal of Occupational and Organizational Psychology, 83, 981-1002. doi:10.1348/ 096317909X481382

Vandenberg, R. J., \& Lance, C. E. (2000). A review and synthesis of the measurement invariance literature: Suggestions, practices, and recommendations for organizational research. Organizational Research Methods, 3, 4-70. doi:10.1177/109442810031002

Vansteenkiste, M., Lens, W., De Witte, S., De Witte, H., \& Deci, E. L. (2004). The "why" and "why not" of job search behaviour: Their relation to searching, unemployment experience, and well-being. European Journal of Social Psychology, 34, 345-363. doi:10.1002/ ejsp.202

Vansteenkiste, M., Neyrinck, B., Niemiec, C. P., Soenens, B., De Witte, H., \& Van Den Broeck, A. (2007). On the relations among work value orientations, psychological need satisfaction, and job outcomes: A self-determination theory approach. Journal of Occupational and Organizational Psychology, 80, 251-277. doi:10.1177/0013164497057006009

Wang, Z., \& Gagné, M. (2013). A Chinese-Canadian cross-cultural investigation of transformational leadership, autonomous motivation and collectivistic value. Journal of Leadership and Organizational Studies, 20, 134-142. doi:10.1177/1548051812465895

Original manuscript received April 2013 Revised manuscript received December 2013 Revised manuscript accepted December 2013 First published online January 2014 


\section{APPENDIX}

The Multidimensional Work Motivation Scale (MWMS)

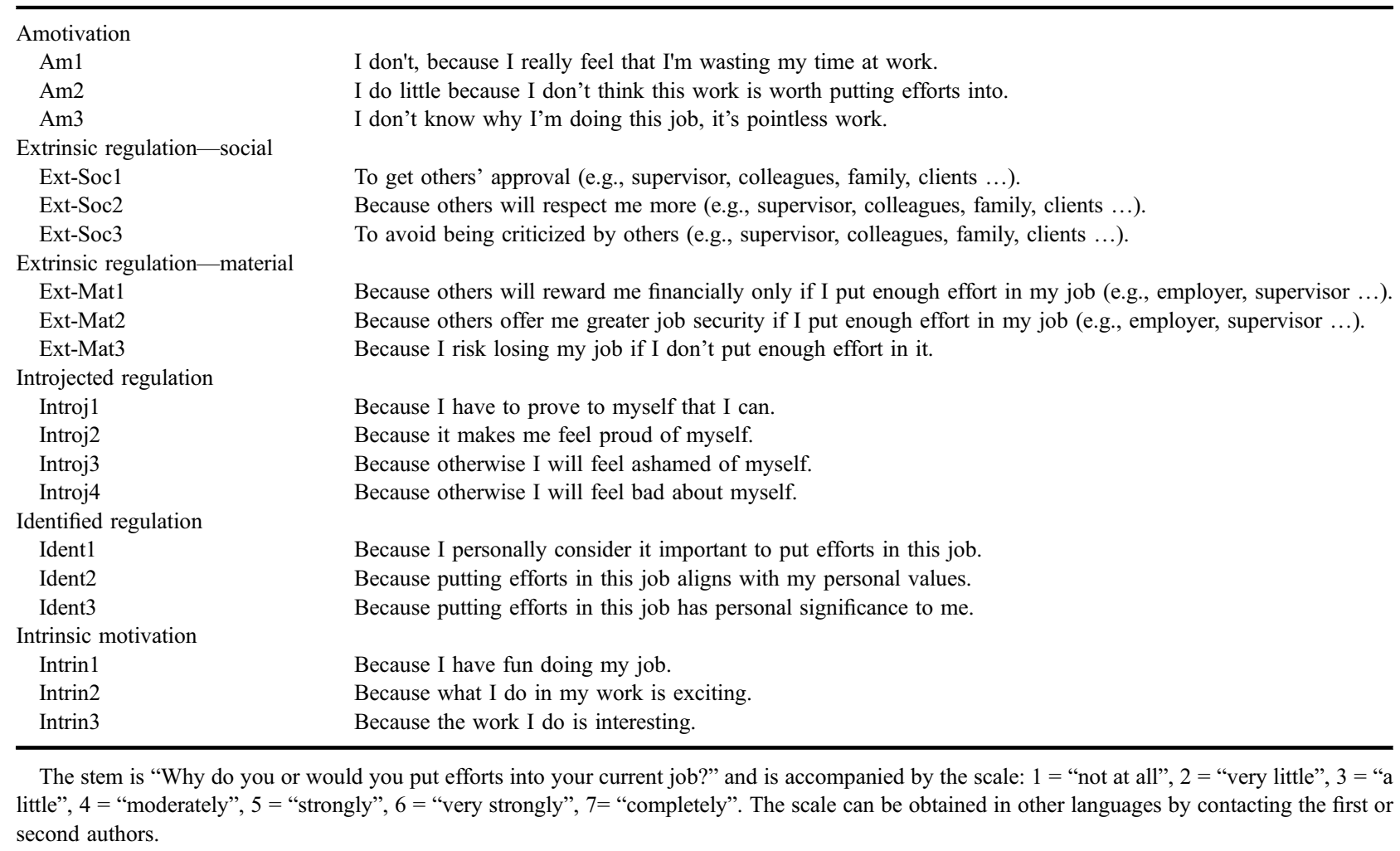

